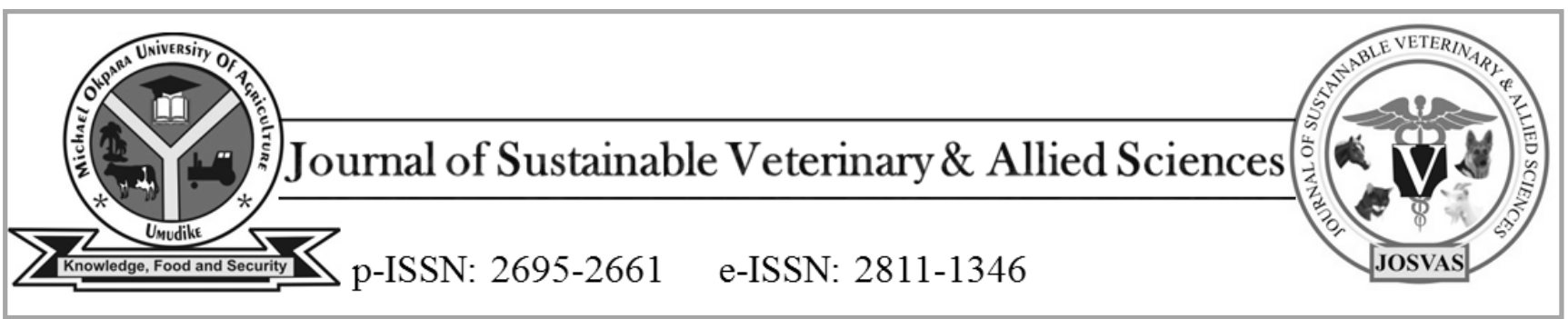

JoSVAS 2021, Vol 1, Issue 1: 67-72

C2021 College of Veterinary Medicine,

Michael Okpara University of Agriculture, Umudike, Nigeria

Original Research Article

\title{
Vertebral heart size and cardiosternal contact evaluation in thoracic roentgenographs of the Nigerian indigenous dog

\author{
${ }^{1}$ *Ukaha R.O., ${ }^{2}$ Kene R.O.C. $\&{ }^{3}$ Agwu, K.K.
}

${ }^{I}$ Department of Veterinary Surgery \& Radiology, College of Veterinary Medicine, Michael Okpara University of Agriculture, Umudike, ${ }^{2}$ Department of Veterinary Surgery, Faculty of Veterinary Medicine, University of Nigeria, Nsukka, ${ }^{3}$ Department of Radiography and Radiological Sciences, College of Medicine, University of Nigeria, Enugu Campus, Enugu State, Nigeria.

*Corresponding author: ukarock1@gmail.com; +2348061530565

\begin{abstract}
The aim of this cross-sectional prospective radiologic study was to determine reproducible biometric ratios for cardiac assessment in the indigenous dog. Thirty healthy male and female dogs were used for the study. Sixty right and left lateral thoracic projections of the dogs were acquired. Parameters in each radiograph were objectively evaluated, namely: cardiac long and short axes in right and left lateral views. Indices generated were the vertebral heart size and the cardiosternal contact (also known as intercostal heart size). The mean values of vertebral heart size (VHS) and intercostal heart size (IHS) were: $9.82 \pm 0.08 / 9.70 \pm 0.10$ and $3.40 \pm 0.05 / 3.37 \pm 0.05$ for the right and left lateral radiographs, respectively. Vertebral heart size correlated strongly, positively and significantly with cardiac long and short axes while IHS showed a high, positive and significant relationship with short axis but a moderately, positively significant association with long axis. The indices determined in the study are easy to use and allow for objective investigation of the canine heart. The results of this research are clinically relevant in the diagnosis and management of cardiac anomalies.
\end{abstract}

Keywords: Diagnosis, Nigerian dogs, radiology, thoracic measurements.

\section{INTRODUCTION}

Heart failure and other cardiac conditions are frequently seen in middle-aged and older dogs and cats. Ascites, pleural effusion and peripheral oedema are clinical signs of failure of the right ventricle, while left ventricular failure is associated with pulmonary oedema (Knight, 1989; Moon, 2006). Patent ductus arteriosus (PDA) is common in dogs and thoracic radiographs of affected animals often reveal cardiac enlargement. Radiographic signs of long standing PDA are marked left ventricular and left atrial enlargement, prominent pulmonary vascular pattern and finally, left-sided heart failure (Darke, 1989). Cardiomegaly is also a common radiographic sign associated with canine patients affected with ventricular septal defect, pulmonic and aortic stenotic conditions, et cetra (Darke, 1989).

Cardiomyopathy and valvular insufficiency are other acquired cardiac anomalies associated with abnormal increase in heart size and shape causing greater than normal cardiosternal contact and abnormal elevation of cardiac apex (Bonagura, 1989; Knight, 1989). Enlarged or globoid canine cardiac silhouette may be due to distension of pericardial sac with pathological fluid, known as pericardial effusion or hydropericardium. In all these disease conditions, diagnosis of the heart size anomalies can be evaluated or supported in thoracic radiographs using thoracic indices such as the vertebral heart score (VHS) as handy guides. The VHS may be most useful for the monitoring or evaluation of changes in cardiac size over a period of time. However, the degree of accuracy of the VHS and subjective evaluation of cardiac anomalies have not been compared (Lamb et al., 2000).

Measurement methods suitable for all-purpose clinical application are yet to be developed, over the years, due to thoracic conformational differences in animal breeds (Hamlin, 1968; Randano \& Alexander, 1976; Holmes et al., 1985; Toombs \& Ogburn, 1985). A reference cardiothoracic ratio reported centuries ago is still used by radiologists, cardiologists and clinicians as a method of cardiac size evaluation in thoracic radiographs (Danzer, 1919, Miller et al., 2000; Baron, 2004). Variations in thoracic conformations, respiratory phase and equivocal measurement 
landmarks are limitations that cannot be ignored to the cardiac thoracic ratio (CTR) guideline. To overcome these limitations, skeletal ratios were explored (Buchanan \& Bucheler, 1995) to establish a more precise, easy-to-use assessment method that is not influenced by respiratory phases.

It has been reported that a satisfactory relationship $(>0.7)$ between the heart sizes generated in thoracic radiographs and postmortem results exists (Murphy et al., 1985). It has equally been demonstrated that an appreciable association exists between heart size and body parameters (Stunzi et al., 1959; Buchanan \& Bucheler, 1995). It was on that basis that, in the research reported here, cardiac dimensions were compared to lengths of middle thoracic vertebrae with a view to developing reference cardiac size for the Nigerian Indigenous Dog.

\section{MATERIALS AND METHODS}

Thirty Nigerian Indigenous Dogs (aged $\geq 7$ months) made up of equal number of both sexes with average body weight of $8.19 \mathrm{~kg}$, and procured from local breeders. The dogs were acclimatized for 30 days, fed, examined and certified healthy by the normalcy of their vital parameters (Straub et al., 2002), before commencement of the study.

Each research dog was restrained chemically with xylazine hydrochloride (XYL-M2®: VMD, Belgium) given at $2 \mathrm{mg} / \mathrm{kg}$ intramuscularly, and physically with foam pads and leg-ties. Manual restraint was never used in this study. Plain thoracic lateral projections were obtained of each animal at the peak of inspiration, namely: right lateral (RtL) and left lateral (LeL) roentgenographs, as described by Douglas et al.

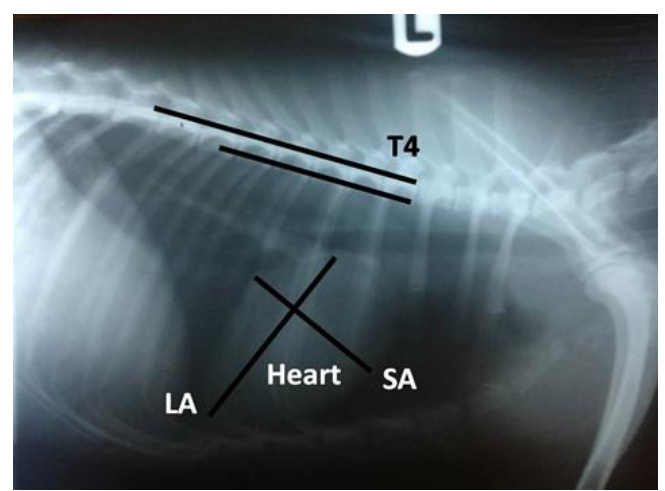

Figure 1. Left lateral thoracic radiograph of the Nigerian Indigenous Dog illustrating measurements of thoracic parameters for the determination of vertebral heart size. LA; cardiac long axis, SA; widest short axis perpendicular to LA, T4; the fourth thoracic vertebra. .
(1987) and Jepsen-Grant et al. (2013) using a mobile x-ray unit (Dean, Dynamax 40, GEC Medical Equipment Group Ltd, England). The focus-film-distance was always set at $90 \mathrm{~cm}$ for all the projections. Other materials used in the study were a viewing box, Begood ${ }^{\circledR}$ (Medical X-ray Blue Sensitive Film, China) brand of X-ray films, cassettes and screens (NACAL Medical, England), and Begood ${ }^{\circledR}$ processing chemicals (developer and fixer powders). Each time, the whole thorax from the first rib to the first lumbar vertebra was exposed. The x-ray beam was centered in the mid-fourth intercostal space (Douglas et al., 1987; JepsenGrant, 2013). Each exposed film was processed and properly stored in an envelope. With the help of a viewing-box, the following silhouette dimensions were measured with a pair of calipers and metre rule: cardiac long axis (LA) or the apicobasilar heart length, cardiac short axis (SA) or the greatest width of heart drawn at right angles to LA, transposition of cardiac axes on to thoracic vertebrae (Figures 1 and II) and the length of cardiosternal contacts (figures III and IV). The data obtained were stored in a computer hard disc and a CD.

To determine the vertebral heart score (VHS), the LA calipers measurement was superimposed on the thoracic vertebrae beginning at the fourth thoracic vertebra (T4). The number of vertebrae taken up by the calipers points was noted to the nearest 0.5 vertebrae. Likewise, the SA calipers measurement was equally transposed on the thoracic vertebrae as described, and the two measurements now in vertebral units were added to generate the VHS (Buchanan and Bucheler, 1995; Litster and Buchanan, 2000; Sleeper and Buchanan, 2001, Bavegems et al., 2005; Jepsen-Grant, 2013).

Secondly, the number of intercostal spaces between the cranial and caudal cardiosternal contact points was recorded to the nearest 0.05 intercostal space for each research radiograph as the intercostal heart size (Kealy, 1987; Bahr,

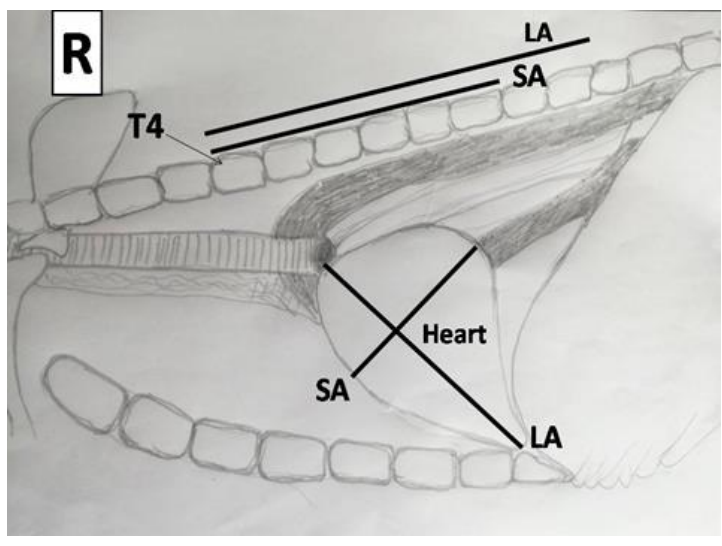

Figure 1I. Annotated diagram of right lateral thoracic view of the Nigerian Indigenous Dog clarifying measurements in Figure I. Abbreviations are defined in Figure 1. 


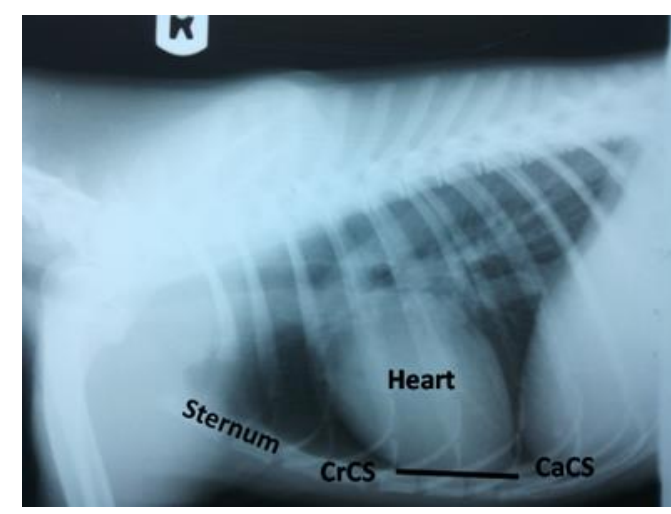

Figure III. Right lateral thoracic radiograph of the Nigerian Indigenous Dog with illustration of parametric measurement method. CrCS; cranial cardiosternal contact point, CaCS; caudal cardiosternal contact point.

2013).

\section{ETHICAL APPROVAL}

All procedures with respect to the housing, environment, handling and management of dogs were carried out in accordance with the ethical standards of College of Veterinary Medicine Research Ethical Committee (MOUAU/CVM/REC/202115) of the Michael Okpara University of Agriculture, Umudike and with the Helsinki Declaration of 1975 revised in 2000.

\section{DATA ANALYSIS}

Data obtained in the study reported here were analyzed using Student's T-test and Pearson's product moment correlation coefficient statistics. The means and standard errors of means were calculated for each age group, sex and for all dogs pooled. Results were presented as means \pm SEM. Statistical significance was defined at $\mathrm{P} \leq 0.05$.

\section{RESULTS}

Mean vertebral units (v) of long axis (LA) were smaller in left lateral view (LeL, 5.33 \pm 0.06$)$ than right lateral (RtL) value $(5.65 \pm 0.05)$, while mean short axis (SA) vertebral units $(4.17 \pm 0.05)$ was smaller in the RtL views $(4.37 \pm 0.06)$ (Table I). The vertebral heart size (VHS) score in RtL was $9.82 \pm 0.08$ and was slightly bigger than its mean value in

Table I: Vertebral heart size in right lateral and left lateral projections of Nigerian Indigenous

Dog; VHS = LA v + SA v.

\begin{tabular}{lll}
\hline $\begin{array}{l}\text { Vertebral heart } \\
\text { size }\end{array}$ & $\begin{array}{l}\text { Right lateral } \\
\text { views }\end{array}$ & $\begin{array}{l}\text { Left lateral } \\
\text { views }\end{array}$ \\
\hline LA v & $5.65 \pm 0.05$ & $5.33 \pm 0.06$ \\
SA v & $4.17 \pm 0.05$ & $4.37 \pm 0.06$ \\
VHS & $9.82 \pm 0.08$ & $9.70 \pm 0.10$ \\
\hline
\end{tabular}

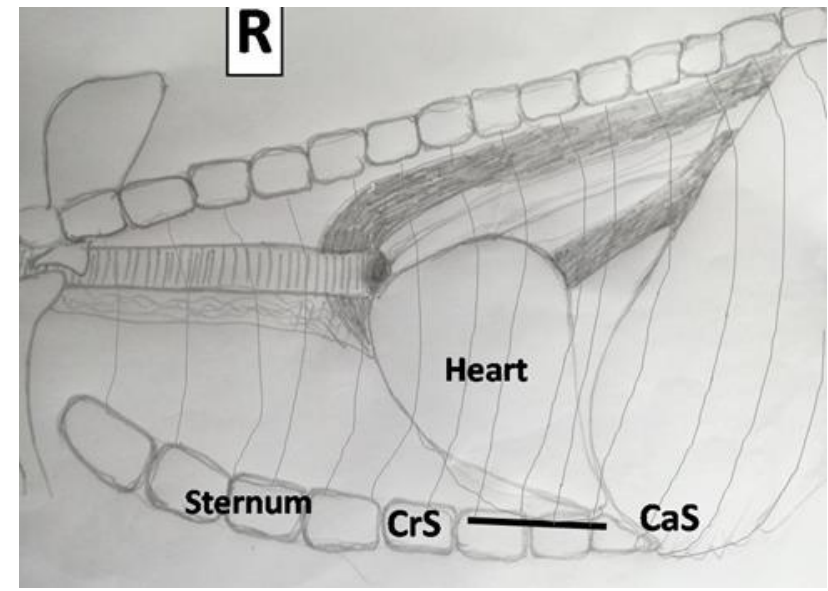

Figure IV. Annotated diagram of lateral thoracic radiograph of the Nigerian Indigenous Dog. Abbreviations are defined in Figure III.

LeL projection $(9.70 \pm 0.10)$. VHS mean scores in RtL and LeL radiographs are not significantly different from each other $(\mathrm{P}>0.05)$.

Results of Vertebral heart size in right lateral and left lateral projections of both sexes of Nigerian Indigenous Dogs are presented in Table II. The long axis view (LA v) for the right and left lateral views in the females were 5.57 \pm 0.07 and $5.27 \pm 0.08$ while the corresponding values for the males were $5.73 \pm 0.08$ and $5.40 \pm 0.07$ respectively. Conversely, the number of vertebrae superposed by short axis (SA) measurement was larger in the LeL radiographs. In both sexes, the vertebral heart size (VHS) mean scores are slightly greater in the RtL $9.70 \pm 0.08$ for male and $9.93 \pm 0.13$ for female) than LeL views which were $9.57 \pm 0.13$ and $9.83 \pm 0.14$ respectively. VHS means between sexes and in RtL versus LeL projections were not significantly different from each other $(\mathrm{P}>0.05)$.

Vertebral heart size (VHS) mean scores were slightly greater in right lateral (RtL) views in both the age brackets, compared with the left lateral (LeL) mean values (Table III). The VHS values of adult RtL and LeL views were $9.83 \pm 0.10 \mathrm{v}$ and $9.66 \pm 0.11 \mathrm{v}$ respectively. And these were not significantly $(\mathrm{P}>0.05)$.different from corresponding values in puppies.

Mean intercostal heart size (IHS) value of right RtL was

Table 1I: Sexual difference in vertebral heart size, VHS. $\mathbf{L A}=$ cardiac long axis, $\mathbf{S A}=$ short axis, measurements in vertebral units v. VHS = LA vertebrae + SA vertebrae .

\begin{tabular}{lllll}
\hline $\begin{array}{l}\text { Vertebral } \\
\text { heart } \\
\text { sizes }\end{array}$ & $\begin{array}{l}\text { Right } \\
\text { lateral } \\
\text { views } \\
\text { (Females) }\end{array}$ & $\begin{array}{l}\text { Left } \\
\text { lateral } \\
\text { views } \\
\text { (Females) }\end{array}$ & $\begin{array}{l}\text { Right } \\
\text { lateral } \\
\text { views } \\
\text { (Males) }\end{array}$ & $\begin{array}{l}\text { Left } \\
\text { lateral } \\
\text { views } \\
\text { (Males) }\end{array}$ \\
\hline LA v & $5.57 \pm 0.07$ & $5.27 \pm 0.08$ & $5.73 \pm 0.08$ & $5.40 \pm 0.07$ \\
SA v & $4.13 \pm 0.08$ & $4.30 \pm 0.07$ & $4.20 \pm 0.07$ & $4.43 \pm 0.10$ \\
VHS & $9.70 \pm 0.08$ & $9.57 \pm 0.13$ & $9.93 \pm 0.13$ & $9.83 \pm 0.14$ \\
\hline
\end{tabular}


$3.40 \pm 0.05$ which was a greater than $3.37 \pm 0.05$ observed in the LeL view (Table IV). However, there was no significant $(\mathrm{P} \geq 0.05)$ difference between the two values.

Female intercostal heart size (IHS) mean scores were slightly less than male means in both right RtL and LeL radiographs (Table V). No significant difference was observed in the two means $(\mathrm{P}>0.05)$.

Mean intercostal heart size (IHS) scores were slightly greater for puppies than the mean scores for adult dogs in both right lateral and left lateral views (Table VI). ReL and LeL for puppies were $3.80 \pm 0.16$ and $3.80 \pm 0.16$ respectively. There was no significantly difference between adults' and puppies' values $(\mathrm{P}>0.05)$. The ratios of the RtL and LeL of VHS and IHS in males, females, adult and puppy are summarized in Table VII. The results of correlation (Tables VIII) as

Table III: Age differences in vertebral heart size in right lateral and left lateral projections of Nigerian Indigenous Dogs

\begin{tabular}{lllll}
\hline VHS & RtL & LeL (Adult & $\begin{array}{l}\text { RtL } \\
\text { (Puppies) }\end{array}$ & LeL \\
& $\begin{array}{l}\text { (Adult } \\
\text { dogs) }\end{array}$ & dogs) & & \\
& & & & \\
\hline LA v & $5.68 \pm 0.08 \mathrm{v}$ & $5.33 \pm 0.08 \mathrm{v}$ & $5.60 \pm 0.64 \mathrm{v}$ & $5.35 \pm 0.62 \mathrm{v}$ \\
SA v & $4.15 \pm 0.05 \mathrm{v}$ & $4.33 \pm 0.06 \mathrm{v}$ & $4.20 \pm 0.49 \mathrm{v}$ & $4.45 \pm 0.52 \mathrm{v}$ \\
VHS & $9.83 \pm 0.10 \mathrm{v}$ & $9.66 \pm 0.11 \mathrm{v}$ & $9.80 \pm 1.13 \mathrm{v}$ & $9.80 \pm 1.12 \mathrm{v}$ \\
\hline
\end{tabular}

Table IV: Intercostal heart size (IHS) in right lateral and left lateral views of Nigerian Indigenous Dog.

\begin{tabular}{lll}
\hline $\begin{array}{l}\text { Intercostal heart } \\
\text { size }\end{array}$ & $\begin{array}{l}\text { Right lateral } \\
\text { views }\end{array}$ & $\begin{array}{l}\text { Left lateral } \\
\text { views }\end{array}$ \\
\hline IHS & $3.40 \pm 0.05$ & $3.37 \pm 0.05$ \\
\hline
\end{tabular}

Tab;e V. Sex differences in intercostal heart size in right lateral and left lateral views of Nigerian Indigenous Dogs

\begin{tabular}{lll}
\hline Lateral views & $\begin{array}{l}\text { Sex differences in } \\
\text { IHS (Females) }\end{array}$ & $\begin{array}{l}\text { Sex differences } \\
\text { in IHS (Males) }\end{array}$ \\
\hline $\begin{array}{l}\text { Right lateral } \\
\text { views }\end{array}$ & $3.27 \pm 0.14$ & $3.53 \pm 0.19$ \\
$\begin{array}{l}\text { Left lateral } \\
\text { views }\end{array}$ & $3.23 \pm 0.14$ & $3.50 \pm 0.20$ \\
\hline
\end{tabular}

Table VI: Age differences in intercostal heart size determined in right lateral and left lateral views of Nigerian Indigenous Dogs

\begin{tabular}{rll}
\hline Lateral views & $\begin{array}{l}\text { Age difference in } \\
\text { IHS (Adults) }\end{array}$ & $\begin{array}{l}\text { Age difference } \\
\text { in IHS } \\
\text { (Puppies) }\end{array}$ \\
\hline $\begin{array}{r}\text { Right lateral } \\
\text { views }\end{array}$ & $3.20 \pm 0.08$ & $3.80 \pm 0.16$ \\
$\begin{array}{r}\text { Left Lateral } \\
\text { views }\end{array}$ & $3.15 \pm 0.08$ & $3.80 \pm 0.16$ \\
\hline
\end{tabular}

interpreted in Table IX showed a strong, significant positive relationship between VHS and LA, VHS and SA. HIS correlated highly, positively and significantly with SA but moderately, positively, and also significantly with LA

\section{DISCUSSION}

The mean vertebral heart size (VHS) values in the right lateral (RtL) versus left lateral (LeL) views obtained in the present research (Tables I-III and VII) were not significantly varied from each other between sexes, ages and radiographic projections. However, the pooled VHS means in both RtL and LeL views compared favourably with the value $(9.7 \pm 0.5$ vertebrae) for an exotic dog breed reported by Buchanan and Bucheler (1995) and the mean (9.6 \pm 0.75$)$ subsequently recorded for puppies by Olatunji-Akioye and Alabi (2015), but higher than results $7.5 \pm 0.3$ vertebrae reported for adult cats, 9.4 \pm 0.7 vertebrae for bats, and $7.68 \pm 41$ vertebrae for Agouti by Litster and Buchanan (2000), Gardner et al. (2007), and Diniz et al. (2013), respectively. The results of this investigation were also comparable to the records of $9.7 \pm 0.8$ vertebrae, $9.8 \pm 0.1$ vertebrae, and $9.7 \pm 0.5$ vertebrae in other documents for the German Shepherd Dog, Rottweiler and Daschund, respectively (Lamb et al., 2001; Marin et al., 2007; Jepsen-Grant et al., 2013). In 2001, Sleeper and Buchanan published VHS measurements of $10.0 \pm 0.5$ vertebrae, $9.8 \pm 0.4$ vertebrae, $9.9 \pm 0.6$ vertebraeand $10.3 \pm 0.6$ vertebrae in the same $11 \mathrm{dogs}$ at different ages of 3 , 6,12 , and 36 months, respectively. These mean values were not significantly different from each other, according to the authors, and from the results of our investigation.. The cutoff points in cats and dogs are reported to be 8.1 and 10.77 thoracic vertebrae above which measurements cardiomegaly is considered present. However, Dennis et al. (2010) disclosed that, in some breeds (Labrador, Golden Retriever, Spaniel, Grey Hounds, etc), this cut-off value is commonly exceeded in normal dogs. We feel the normal-abnormal

Table 3: Sex and age distribution of cardiac indices in the Nigerian Indigenous Dog: VHS = vertebral heart size; IHS = intercostal heart size; $\mathbf{n}=$ number of radiographs studied; SEM = standard error of mean.

\begin{tabular}{|c|c|c|}
\hline $\begin{array}{l}\text { Individual } \\
\text { Group } \\
\text { (Number) } \\
\end{array}$ & $\begin{array}{c}\text { VHS (RtL/LeL) } \\
\text { Mean } \pm \text { SEM } \\
\text { (Range in RtL/LeL) }\end{array}$ & $\begin{array}{c}\text { IHS }(\text { RtL/LeL) } \\
\text { Mean } \pm \text { SEM } \\
(\text { Range in RtL/LeL) }\end{array}$ \\
\hline $\begin{array}{c}\text { Male } \\
(n=15)\end{array}$ & $\begin{array}{c}\mathbf{9 . 9} \pm \mathbf{0 . 1 3} / \mathbf{9 . 8} \mathbf{8} \mathbf{0 . 1 4} \\
(9.0-10.5 / 9.0-10.5)\end{array}$ & $\begin{array}{r}\mathbf{3 . 5} \pm \mathbf{0 . 1 4} / \mathbf{3 . 5} \pm \mathbf{0 . 1 4} \\
(2.5-5.0 / 2.5-5.0) \\
\end{array}$ \\
\hline $\begin{array}{l}\text { Female } \\
(n=15)\end{array}$ & $\begin{array}{c}\mathbf{9 . 7} \pm \mathbf{0 . 0 8} / \mathbf{9 . 6} \pm \mathbf{0 . 1 3} \\
(9.0-10.5 / 8.5-10.5)\end{array}$ & $\begin{array}{r}\mathbf{3 . 3} \pm \mathbf{0 . 1 9} / \mathbf{3 . 2} \pm \mathbf{0 . 2 0} \\
(3.0-5.0 / 3.0-5.0)\end{array}$ \\
\hline $\begin{array}{c}\text { Adult } \\
(\mathbf{n}=\mathbf{2 0})\end{array}$ & $\begin{array}{c}\mathbf{9 . 8} \pm \mathbf{0 . 1 0} / \mathbf{9 . 7} \mathbf{\mathbf { 0 } . 1 1} \\
(9.0-10.5 / 8.5-10.5) \\
\end{array}$ & $\begin{array}{r}\mathbf{3 . 2} \pm \mathbf{0 . 0 8} / \mathbf{3 . 2} \pm \mathbf{0 . 0 8} \\
(2.5-4.0 / 2.5-4.0) \\
\end{array}$ \\
\hline $\begin{array}{l}\text { Puppy } \\
(\mathrm{n}=10)\end{array}$ & $\begin{array}{c}\mathbf{9 . 8} \pm \mathbf{0 . 1 3} / \mathbf{9 . 8} \mathbf{8} \mathbf{0 . 1 2} \\
(9.5-10.5 / 9.0-10.5)\end{array}$ & $\begin{array}{c}\mathbf{3 . 8} \pm \mathbf{0 . 1 6} / \mathbf{3 . 8} \pm \mathbf{0 . 1 6} \\
(3.0-5.0 / 3.0-5.0) \\
\end{array}$ \\
\hline $\begin{array}{l}\text { Pooled } \\
(\mathrm{n}=30)\end{array}$ & $\begin{array}{c}\mathbf{9 . 8} \pm \mathbf{0 . 0 8} / \mathbf{9 . 7} \pm \mathbf{0 . 1 0} \\
(9.0-10.5 / 8.5-10.5)\end{array}$ & $\begin{array}{c}\mathbf{3 . 4} \mathbf{4} \mathbf{0 . 0 5} / \mathbf{3 . 4} \pm \mathbf{0 . 0 5} \\
(2.5-5.0 / 2.5-5.0)\end{array}$ \\
\hline
\end{tabular}


Table VIII. Pearson's Correlation Coefficient of Indices: vertebral heart size, VHS and intercostal heart size, IHS with cardiac parameters: long axis LA and short axis $\mathrm{SA}$, * = significant correlation.

\begin{tabular}{llllcccccc}
\hline Index & \multicolumn{1}{c}{ LA SA } & VD & ThI & CD & CL & TD & CC \\
\hline VHS & P. Correlation & $.800^{* * *}$ & $.756^{* *}$ & -.253 & -.349 & -.138 & -.141 & -.284 & $-.477^{* *}$ \\
& Sig. (2-tailed) & .000 & .000 & .177 & .058 & .465 & .458 & .128 & .008 \\
& N & 30 & 30 & 30 & 30 & 30 & 30 & 30 & 30 \\
\hline IHS & P. Correlation & $.401^{*}$ & $.645^{* * *}$ & $-.607^{* *}$ & $-.470^{* *}$ & $-.574^{* *}$ & $-.596^{* *}$ & $-.688^{* *}$ & $-.654^{* *}$ \\
& Sig. (2-tailed) & .028 & .000 & .000 & .009 & .001 & .001 & .000 & .000 \\
& N & 30 & 30 & 30 & 30 & 30 & 30 & 30 & 30 \\
\hline
\end{tabular}

Table IX. Guidelines for Determination of IndexParameter Association:

\begin{tabular}{llc}
\hline & \multicolumn{2}{c}{ Coefficient, $r$} \\
\cline { 2 - 3 } Strength of Association & Positive & Negative \\
\hline Small & .1 to .3 & -0.1 to -0.3 \\
Medium & .3 to .5 & -0.3 to -0.5 \\
Large & .5 to 1.0 & -0.5 to -1.0 \\
\hline
\end{tabular}

result-overlaps may most probably be due to thoracic conformational breed differences. The VHS was originally developed as a screening test for cardiomegaly; Nakayama et al. (2001) even reported that VHS results were obviously comparable with electrocardiographic and echocardiographic parameters. However, other authors believe that the scale functions best as a means to detect changes and monitor cardiac disease progression or response to treatment (Thrall, 2002; Gardner et al., 2007).

In average exotic dogs, the amount of cardiac contact with sternum ranges from 2.5 to 3.0 intercostal spaces; thus a sternal contact exceeding 3.0 intercostal spaces is suggestive of right ventricular hypertrophy. Deep-chested breeds, such as Doberman pinschers may have 1.5 to 2.0 intercostal spaces of sternal contact, while some barrel-chested breeds e.g. bulldog, can normally have more than 3.0 to 3.5 intercostal spaces of cardiac contact (Owens, 1985; Kealy, 1987; Bahr, 2013). This report agrees with the intercostal heart size (IHS) results (Tables $2 \mathrm{a}-\mathrm{c}$ and 3 ) determined in the present research. These results compare very well with the findings in barrel-chested dogs. Any IHS value outside of the ranges is likely indicative of cardiac size anomaly. Hypertrophy of the right ventricle can also lead to dorsal displacement of cardiac apex from the sternum in lateral radiographs, but in dorsal versus ventral views, the hypertrophic right ventricle appears more rounded and protrudes farther into the right hemithorax than normal, giving the cardiac silhouette reversed letter " $D$ " shape (Bahr, 2013). Though slightly greater in the pooled, sex, and age values (Tables I-III), the mean RtL VHS results were not significantly different from the LeL values $(p \geq 0.05)$. The mean IHS values were also not significantly different between sexes, ages, and views ( $\mathrm{p} \geq 0.05)$ (Tables IV-VI).

The results of this study showed a strong, significant positive relationship between VHS and LA, VHS and SA. IHS correlated highly, positively and significantly with SA but moderately, positively, and also significantly with LA.

Analysis of thoracic radiographs by morphometric measurements is more accurate than the use of subjective impression especially in subclinical and subtle diseases associated with organ (such as cardiac) size anomalies. The mean index results obtained in this research may be useful guidelines in small animal clinical practice for comparison and assessment of the heart in the Nigerian Indigenous Dog

\section{CONFLICT OF INTERST}

The authors have no conflict of interest to declare.

\section{REFERENCES}

Atata J.A., Esievo K.A.N., Adamu S., \& Abdusalam H. (2018): Baseline haematological, serum biochemical and some urine parameters in Nigerian Indigenous Dogs; Savannah Veterinary Journal 1:1-5.

Bahr, R. (2013). The heart and pulmonary vessels. In: Thrall DE (Ed.) Textbook of Veterinary Diagnostic Radiology (6th ed., pp585-605). St Louis: Saunders Elsevier Inc.

Baron, M.G. (2004). Radiology of the heart. In: Cecil Textbook ofMedicine. http://www.merckmedicus.com Retrieved 25 August, 2019.

Bavegems, V., Caelenberg A.V., Duchateau, L, Sys, S.U., Bree, H.V. \& DeRick, A. (2005). Vertebral heart size ranges specific for Whippets. Veterinary Radiology \& Ultrasound, 46, 400-403.

Bonagura, J.D. (1989). Congenital heart disease.

Textbook of Veterinary Internal Medicine Vol I (3rd ed.). Philadelphia, WB Saunders Co.

Buchanan, J.W. \& Bucheler, J. (1995). Vertebral scale system to measure canine heart size in radiographs. Journal of American Veterinary Medical Association, 206, 194.

Danzer C.S. (1919). The cardiothoracic ratio: An index of cardiac enlargement. American Journal of Medical Sciences, 157:513.

Darke, P.G.G. (1980). Cardiac disease syndromes in dogs and cats. In Practice, 2(3), 5-12. 
Dennis, R., Kirberger, R.M., Barr, F. \& Wrigley, R.H.

(2010). Other thoracic structures: pleural cavity, mediastinum, thoracic oesophagus, thoracic wall. In: Handbook of Small Animal Radiology and Ultrasound: Techniques and Differential Diagnoses (2nd edn., pp199-226.). Churchill Livingstone Elsevier, London.

Diniz., A., da Silva, Jr J., Ambrosio, C., de Sousa J., de Sousa, V., Cavalho, M., Nascimento, D. \& Alves, F (2013). Thoracic and heart biometrics of nonanaesthetized agouti (Dasyprocta primnolopha Wagler, 1831) measured on radiographic images. Pesquisa Veterinaria Brasileira, Vol 33 No.3.

Douglas, S.W., Herrtage, M.E. \& Williamson, H.D. (1987). Principles of Veterinary Radiology (Fourth edn.). Bailliere Tindall, London.

Gardner, A., Thompson, M.S., Heard, D.J., Fontenot, D. \& Gibson, N. (2007). Radiographic evaluation of cardiac size in flying fox species (Pteropus rodricensus, $P$. hypomenalus and $P$. vampyrus), Journal of Zoo \& Wildlife Medicine, 38(2),192-200.

Gardner, A., Thompson, M.S., Heard, D.J., Fontenot, D. \& Gibson, N. (2007). Radiographic evaluation of cardiac size in flying fox species (Pteropus rodricensus, $P$. hypomenalus and P. vampyrus). Journal of Zoo and Wildlife Medicine, 38(2), 192-200.

Hamlin RL (1968). Analysis of the cardiac silhouette in dorsoventral radiographs from dogs with heart disease. Journal of American Veterinary Medical Association 153:1444-1460.

Holmes RA, Smith FG, Lewis RE, \& Dennis MK (1985). The effects of rotation on the radiographic appearance of the canine cardiac silhouette in dorsal recumbency. Veterinary Radiology 26:98-101.

Jepsen-Grant, K., Pollard, R.E. \& Johnson, L.R (2013). Vertebral heart scores in eight dog breeds. Veterinary Radiology and Ultrasound, 54(1), 3-8.

Jones, T.C., Hunt, R.D. \& King, N.W. (1997). Veterinary Radiology (6th ed.). Baltimore, Williams \& Wilkins.

Kealy, J.K. \& McAllister, H. (2000). The thorax. Diagnostic Radiology and Ultrasonography of the Dog and Cat (3rd ed., 149 -249). Philadelphia, WB Saunders Co.

Knight, D.H. (1989). Pathophysiology of heart failure. Textbook of Veterinary Internal Medicine, Vol I. (3rd ed.). Philadelphia, WB Saunders Co.

Lamb, C.R., Wikely, H., Boswood, A. \& Pfeiffer, D.U. (2001). Use of breed-specific ranges for the vertebral heart scale as an aid to the radiographic diagnosis of cardiac diseases in dogs. Veterinary Records, 148, 707-711.

Lamb, C.R., Tyler, M., Boswood, A., Skelly, B.J. \& Cain, M. (2000). Assessment of the value of

the vertebral heart scale in the radiographic diagnosis of cardiac disease in dogs.

Veterinary Records, 146(24):687-690.

Litster, A. \& Buchanan, J.W. (2000). Vertebral scale system to measure heart size in radiographs of cats. Journal of American Medical Association, 216, 210-214.

Marin, L.M., Brown, J., McBrien, C., Baumwart, R., Samii, V.F. \& Couto, G. (2007). Vertebral heart size in retired racing Greyhounds. Veterinary Radiology \& Ultrasound 48:332-334.

Miller, J.A., Singer, A., Hinrichs, C., Contractor, S. \& Doddakashi, S. (2000). Cardiac dimensions derived from computed tomography: Correlation with plain film radiography. Internet Journal of Radiology ISSAN: 1528-8404 Vol 1:1. http://www.ispub.com Retrieved 4 August, 2019.

Moon, M. (2006). Radiographic evaluation of the abnormal heart. http://education.vetmed.vt.edu/curriculum /VM8754/moon.html Retrieved 23 July, 2019.

Murphy, M.L., Blue, L.R., Thenabadu, P.N., Phillips, J.R. \& Ferris, E.J. (1985). The reliability of the routine chest roentgenogram for determination of heart size based on specific ventricular chamber evaluation at postmortem. Investigative Radiology, 20(1), 21-5.

Nakayama, H, Nakayama, T. \& Hamlin, R.L. (2001). Correlation of Cardiac enlargement as assessed by vertebral heart size and echocardiography and electrocardiographic findings in dogs with evolving cardiomegaly due to rapid ventricular pacing. Journal of Veterinary Internal Medicine 15:217221.

Olatunji-Akioye, A. \& Alabi, B. (2015). Preliminary assessment of vertebral heart score of the Nigerian mongrel dog. Nigerian Veterinary Journal, 36(4), 1283-1287.

Owens, J.M (1985). Radiology of the Heart. In: Tilley LP\& Owens JM (Eds.). Manual of Small Animal Cardiology. Churchill Livingstone Inc, New York. P37

Randano, V.T. \& Alexander, J.E. (1976). Heart size changes in experimentally-induced adrenal insufficiency in the dog: a radiographic study. Journal of Veterinary Radiology 17:57-66.

Sleeper, M.M. \& Buchanan, J.W. (2001). Vertebral scale system to measure heart size in growing puppies. Journal of American Veterinary Medical Association 219(1): 57-59.

Straub, J., Pees, M. \& Krautwald-Junghanns, M.E. (2002). Measurement of the cardiac silhouette in psittacines. Journal of American Veterinary Medical Association. 221(1):76-79.

Stunzi, H., Teuscher, E. \& Bolllger, O. (1959). Systematische Un- tersuchungen am Herzen von Haustieren. 1. Mitteilung: Unter- suchung am Herzen der Katze. Zent. Zentralbl Veteindrmed 6:10 1-117

Thrall, D.E. (2002). Interpretation paradigms for the small animal thorax. In: Thrall DE (ed) Textbook of Veterinary Diagnostic Radiology (Fourth edn, pp 318-319.).WB Saunders Co., Philadelphia, Pennsylvania.

Toombs JP \& Ogbum PN (1985). Evaluating canine cardiovascular silhouettes: radrographic methods and normal radiographic anatomy. Compendium of Continuing Education for Practising Veterinarians 7:579-587

Article history:

Received: May 12, 2021,

Revised: August 15, 2021, Accepted: August 27, 2021 